\title{
PRODUÇÃO DE SERAPILHEIRA SOB PLANTIO DE HÍBRIDOS DE Eucalyptus, ALIANÇA DO TOCANTINS - TOCANTINS
}

Litter production in hybrid Eucalyptus plantatings, Aliança do Tocantins - Tocantins

Producción de serapillera bajo plantios de híbridos de Eucalyptus, Aliança do Tocantins - Tocantins

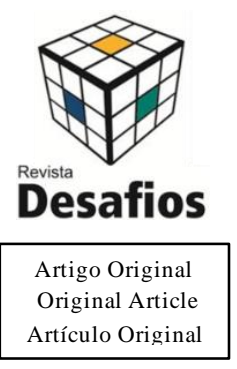

Paulo Ricardo Teixeira*1, Rômullo Quirino de Souza Ferreira ${ }^{1}$, Marilia Oliveira Camargo ${ }^{1}$, Rodrigo de Castro Tavares ${ }^{1}$, Priscila Bezerra de Souza ${ }^{1}$

${ }^{1}$ Curso de Engenharia Florestal, Universidade Federal do Tocantins, Gurupi, Tocantins, Brasil.

*Correspondência: Universidade Federal do Tocantins, UFT-Rua Badejós, Lt. 07 Ch. 69/72Zona Rural77402970 Gurupi, TO -Brasil-Caixa-postal: 66.e-mail paulo.engflorestal@ hotmail.com.

Artigo recebido em 29/05/2018 aprovado em 13/09/2019 publicado em 03/10/2019.

\section{RESUMO}

O objetivou-se verificar a produção de serapilheira sob dois plantios E. urocam e E. urograndis, inseridos no domínio Cerrado, Aliança do Tocantins - TO. O estudo foi desenvolvido na fazenda Nossa Senhora Parecida, Aliança do Tocantins - TO, sob as coordenadas 11'21'53 S e 49'02'54 O. Foram instalados aleatoriamente em cada um dos plantios dez coletores de 1 x $1 \mathrm{~m}$. Os coletores foram sustentados por estacas com $0,80 \mathrm{~m}$ de altura do solo, os quais foram monitorados mensalmente durante o período de maio 2015 a abril de 2016. As amostras coletadas foram secas e separadas em frações de folha e material lenhoso. A produção média de serapilheira total entre os dois plantios apresentou-se bem variável com uma produção anual de $3274,5 \mathrm{~kg} \mathrm{ha}^{-1}$ no plantio de $E$. urocame de $3523 \mathrm{~kg} \mathrm{ha}^{-1}$ no plantio de E. urograndis. A fração mais representativa da serapilheira total encontrada nos dois plantios estudados foi composta por folhas, que perfazem $51,2 \%$ do total de material depositado nos coletores enquanto que a fração material lenhoso contribuiu com 48,8\%. Em ambos os plantios o maior aporte de folhas ocorreu no período de maior precipitação (maio, novembro e dezembro de 2015 e janeiro a abril de 2016).

Palavras-chave: avaliação sazonal, serapilheira acumulada, floresta plantada.

\section{ABSTRACT}

The objective was to verify the production of litter in two plantations of E. urocam and E. urograndis inserted into the Cerrado Biome, Aliança do Tocantins - TO. The study was conducted at the farm Nossa Senhora Aparecida, Aliança do Tocantins - TO, under the coordinates 11"21'53 S and 49" 02 '54 W. Ten collectors of $1 \times 1 \mathrm{~m}$ were randomly installed in each plantation. The collectors were supported by piles with 0.80 moff the ground, which were monitored monthly during the period May 2015 to April 2016. The collectors were supported by $0.80 \mathrm{~m}$ height piles, which were monitored monthly during the period from May 2015 to April 2016. The samples were dried and separated into leaf and timber material fractions. The average production of total litter between the two stands showed quite varied with an annual production of $3274.5 \mathrm{~kg} \mathrm{ha}^{-1}$ in the E. urocam stand and $3523 \mathrm{~kg} \mathrm{ha}^{-1}$ in the E. urograndis stand. The most representative fraction of the total litter found in both stands studied consisted of leaves that make up $51.2 \%$ of the material deposited in the collector while the timber material fraction contributed 48.8\%. In both stands, the greatest contribution of leaves occurred in the period of highest rainfall (May, November and December 2015 and January to April 2016).

Keywords: Seasonal assessment, accumulated litter, planted forest. 


\section{RESUMEN}

Se objetivó verificar la producción de arpillera bajo dos plantíos E. urocam y E. urograndis, insertados en el dominio Cerrado, Aliança do Tocantins - TO. El estudio fue desarrollado en la hacienda Nuestra Señora Parecida, Aliança do Tocantins - TO, bajo las coordenadas 11 "21'53 S y 49" 02'54 O. Fueron instalados aleatoriamente en cada uno de los plantíos diez recolectores de $1 \times 1 \mathrm{~m}$. Los colectores fueron sostenidos por estacas con 0,80 $\mathrm{m}$ de altura del suelo, los cuales fueron monitoreados mensua lmente durante el período de mayo 2015 a abril de 2016. Las muestras recolectadas fueron secas y separadas en fracciones de hoja y material leñoso. La producción media de serapillera total entre los dos plantíos se presentó bien variable con una producción anual de $3274,5 \mathrm{~kg} \mathrm{ha}^{-1}$ en la plantación de E. urocam y de $3523 \mathrm{~kg} \mathrm{ha}^{-1}$ en la plantación de E. urograndis. La fracción más representativa de la serapillera total encontrada en los dos plantíos estudiados fue compuesta por hojas, que totalizan el 51,2\% del total de material depositado en los colectores mientras que la fracción material leñosa contribuyó con el 48,8\%. En ambas plantaciones el mayor aporte de hojas ocurrió en el período de mayor precipitación (mayo, noviembre y diciembre de 2015 y enero a abril de 2016).

Descriptores: evaluación estacional, serapillera acumulada, bosque plantado.

\section{INTRODUÇÃO}

No Brasil a região de Cerrado cobre aproximadamente 2 milhões de $\mathrm{Km}^{2}$, cerca de $25 \%$ do território nacional, onde boa parte possui potencial para a agricultura e silvicultura. O Eucalyptus é um gênero que possui espécies com um ciclo de crescimento rápido e tem grande importância comercial no cenário nacional, sendo que estas espécies possuem boa adaptação ao clima e solos do Cerrado que em sua maioria são solos de baixa fertilidade (Oliveira et al., 2000).

Já existem muitos plantios no Cerrado de Minas Gerais e São Paulo, no entanto, é visível o crescimento de plantios de Eucalyptus no bioma Cerrado do Estado do Tocantins. Pesquisas feitas pela Embrapa Florestas apontam o Tocantins como o Estado que vem apresentando o maior crescimento na silvicultura do país. (Seagro, 2012).

Tendo em vista que cada espécie tem características distintas, estas possuem uma variação no aporte da serapilheira sobre o solo de plantios florestais (Watzlawick et al., 2002). Segundo (Sayer, 2005) a serapilheira ajuda na infiltração da água no solo, pois evita a ruptura dos agregados do solo ao impedir sua compactação superficial, pois a serapilheira evita o contato direto da gota de chuva com o solo.

O estudo e conhecimento da quantificação da biomassa de diferentes espécies de Eucalyptus é de fundamental importância, pois fornecem indicativos da capacidade produtiva, indicadores de impactos causados por técnicas silviculturais, bem como fornece informações para posteriores estudos da dinâmica da ciclagem de nutrientes nos diferentes compartimentos do ecossistema (Reis e Barros, 1990; Caldeira et al., 2008).

$\mathrm{O}$ aporte de serapilheira pode ser influenciado por vários fatores abióticos como precipitação, evapotranspiração, aspectos edáficos, temperatura e radiação solar (Santana et al., 2009) e bióticos como estrutura da vegetação, composição florística e estagio sucessional (Werneck et al., 2001). O conhecimento desses fatores é de fundamental importância para que se possa proporcionar um manejo sustentável dos solos e dos recursos florestais empregados em tais culturas.

Tendo em vista a expansão da implantação dos plantios de Eucalyptus no Estado do Tocantins, poucos estudos têm sido realizados no bioma Cerrado, região norte do país. 
Portanto, objetivou-se quantificar a produção de serapilheira ao longo de um ano, sob plantios de Eucalyptus, sendo um E. urocam e outro de $E$. urograndis, Aliança do Tocantins - TO, com intuito de oferecer informações valiosas para o manejo e práticas silviculturais em florestas plantadas no domínio Cerrado, Tocantins.

\section{MATERIAIS E MÉTODOS}

O estudo foi realizado em uma área de 45 ha onde foi feito o plantio de dois híbridos do gênero Eucalyptus, sendo eles de E. urocame E. urograndis. Os plantios foram conduzidos num espaçamento de 3 x $2 \mathrm{~m}$, possuindo uma densidade média de 1666 indivíduos por hectare e idade média de 72 meses. Ambos os plantios de Eucalyptus, estão inseridos no domínio Cerrado, dentro dos limites da propriedade privada Nossa Senhora Aparecida município de Aliança do Tocantins - TO sob as coordenadas geográficas 11"21'53 S e 49”02'54 W, com altitude entre as cotas de 250 a 300 metros.

O clima da região segundo Köppen é do tipo AW, definido como tropical úmido com estação chuvosa no verão e seca no inverno. Os dados de precipitação pluviométrica utilizados na pesquisa foram obtidos na Estação Agrometeorológica da Universidade Federal do Tocantins, Campus de Gurupi - TO, perfazendo o período de maio de 2015 a abril de 2016. A precipitação registrada durante o período avaliado foi de $1179,7 \mathrm{~mm}$ e temperatura média ao longo do ano variou entre $24,6^{\circ} \mathrm{C}$ a $29,7^{\circ} \mathrm{C}$.

Foram instalados aleatoriamente em cada um dos povoamentos de Eucalyptus urograndis e de Eucalyptus urocam dez coletores de 1 x $1 \mathrm{~m}$, com fundo de tela tipo sombrite $50 \%$ e profundidade de $0,10 \mathrm{~m}$. Os coletores foram sustentados por estacas com $0,80 \mathrm{~m}$ de altura do solo. $\mathrm{O}$ material vegetal depositado nos coletores foi retirado mensalmente, durante o período de maio de 2015 a abril de 2016.
Dessa forma o material coletado foi acondicionado em sacos plásticos, etiquetados e conduzidos ao laboratório de Ecologia da UFT, onde foi triado nas seguintes frações folha e material lenhoso, sequencialmente o material foi acondicionado em sacos de papel, etiquetados e levados à estufa com circulação de ar a $65^{\circ} \mathrm{C}$ por 48 horas para secagem. Para obtenção dos valores de massa seca de cada fração da serapilheira foi utilizado uma balança analítica, com precisão de duas casas decimais.

Com os dados obtidos nos coletores de cada plantio de Eucalyptus urograndis e de Eucalyptus urocam, foi calculado para cada coleta, as médias da serapilheira total e de suas frações.

Os dados foram submetidos a análises de variância com aplicação do teste F. As comparações entre as médias dos tratamentos dos dois plantios foram feitas pelo uso do teste de Scott-Knott a 5\% de probabilidade utilizando o aplicativo computacional SISVAR (Ferreira, 2008).

\section{RESULTADOS E DISCUSSÃO}

Pode-se observar no período de maio de 2015 a abril de 2016 que os maiores valores de precipitação foram registrados nos meses de novembro de 2015, janeiro e março de 2016, onde registrou-se uma precipitação anual de $1179,7 \mathrm{~mm}$. A temperatura máxima registrada foi nos meses de setembro e outubro de $2015\left(29,2{ }^{\circ} \mathrm{C}\right.$ e $29,7{ }^{\circ} \mathrm{C}$ respectivamente) e a mínima no mês de junho de $201524,6{ }^{\circ} \mathrm{C}$ (Figura 1).

Vale ressaltar que nos meses de junho a setembro de 2015 ocorreu um período extremamente seco, em que os três primeiros meses citados coincidiram com as temperaturas mais baixas (Figura 1), evento típico das regiões do domínio Cerrado (Carreira, 2004; Rondon, 2006). 
Além dos dados do presente estudo corroborarem com os autores supracitados, deve-se considerar que durante o período de estudo o país foi acometido por um fenômeno chamado "El ninho" que segundo (Mello, 1999) este fenômeno é provocado por maior aquecimento do Oceano Pacifico, resultando em alterações no regime de precipitações atmosféricas de todo globo terrestre, no Brasil, incide uma diminuição da precipitação nas regiões Norte e Nordeste, e um acréscimo da precipitação na região Sul.

Figura 1. Temperatura e precipitação registrada no período de maio de 2015 a abril de 2016. Dados coletados na estação meteorológica da Universidade Federal do Tocantins, Campus de Gurupi - TO.

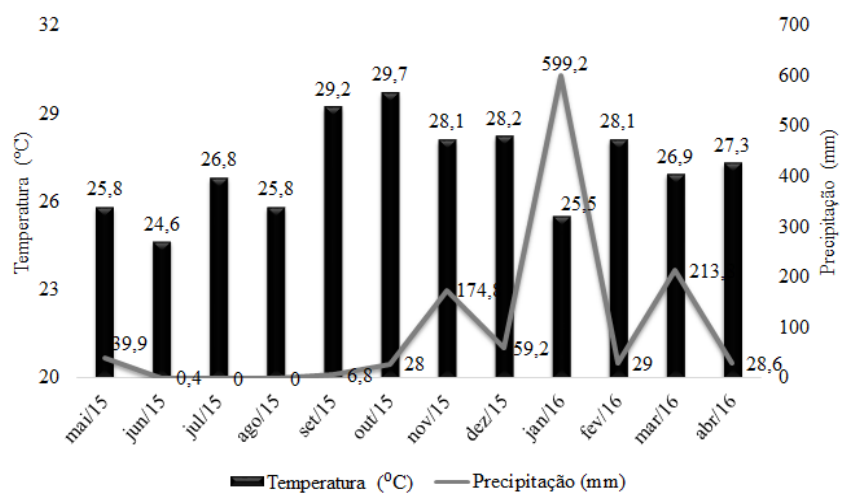

Dessa forma, observou-se uma menor precipitação nos meses de dezembro de 2015, fevereiro e abril de 2016 (52,9 mm, $29 \mathrm{~mm}$ e 28,6 mm respectivamente), já o mês de janeiro de 2016 registrou uma precipitação de 599,2 mm (Figura 1).

A produção média de serapilheira total entre os dois plantios apresentou-se bem variável, sendo que o plantio de E. urocam obteve uma deposição de serapilheira total bem concentrada no mês de fevereiro de 2016 (Figura 2). A deposição de serapilheira total nos meses de maio a julho e dezembro de 2015, janeiro e abril de 2016 mostraram-se semelhantes estatisticamente entre si ao nível de $\mathrm{p}<0,05$. Os menores valores de deposição de serapilheira encontrados no plantio de E. urocam foi entre os meses de agosto a novembro de 2015 e março de 2016 (Figura 2).

O plantio de E. urograndis apresentou maior deposição de serapilheira total nos meses de maio e junho de 2015 e abril de 2016. Nos demais meses a produção média entre os dois plantios estudados mostrou-se estatisticamente semelhantes ao nível de $\mathrm{p}<0,05$ (Figura 3).

Figura 2. Produção mensal de serapilheira total, registrada no plantio de E. urocam, Fazenda Nossa Senhora Aparecida, localizada no município de Aliança do Tocantins - TO, no período de maio de 2015 a abril de 2016. Letras iguais nas barras indicam igualdade significativa $(\mathrm{p}<0,05)$.

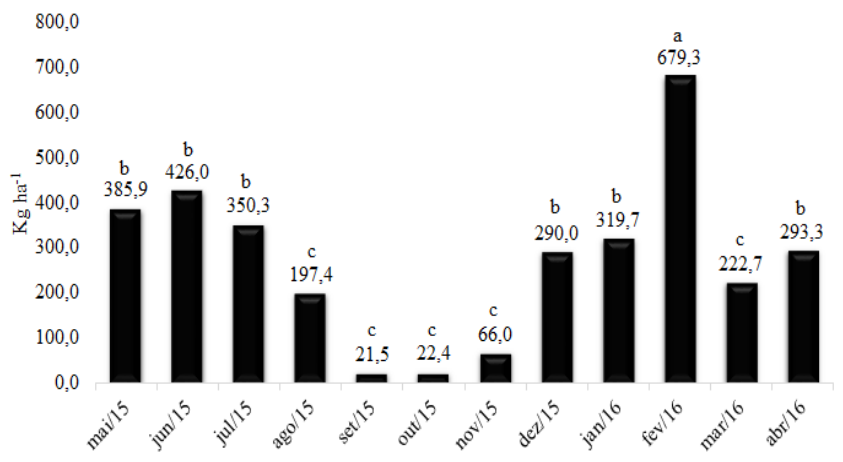

Figura 3. Produção mensal de serapilheira total, registrada no plantio de E. urograndis, Fazenda Nossa Senhora Aparecida, localizada no município de Aliança do Tocantins - TO, no período de maio de 2015 a abril de 2016. Letras iguais nas barras indicam igualdade significativa $(\mathrm{p}<0,05)$.

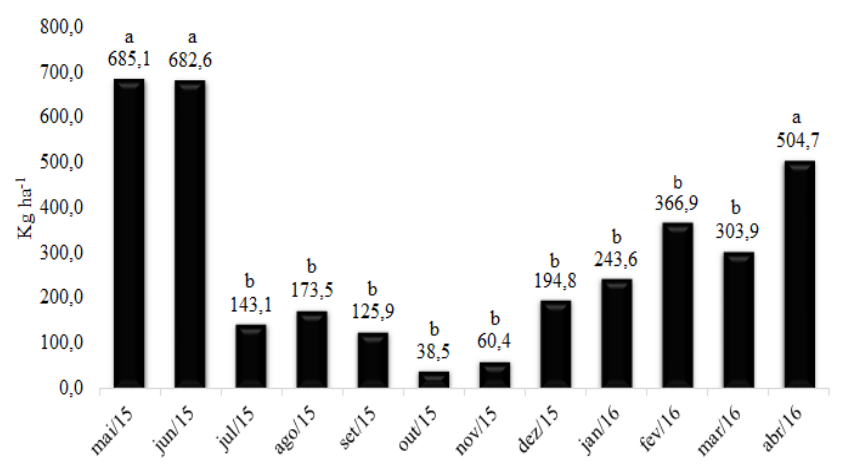

Esta diferença na deposição de serapilheira entre os plantios pode ser explicada devido ao plantio de E. urocam estar sofrendo efeitos de borda, ou seja, condições climáticas adversas com maior incidência de vento e chuvas além do calor excessivo nas bordas, já o plantio de E. urograndis localiza-se no 
interior do plantio, fato este que permite menor incidência de luz e vento consequentemente maior umidade dentro do plantio. Segundo (Correia e Andrade, 2008) o efeito de borda pode levar alterações de condições microclimáticas dentro da floresta, que por sua vez apresenta mudança no aporte e na decomposição da matéria orgânica.

A produção mensal de serapilheira no plantio de E. urocam variou de 21,5 a $679,3 \mathrm{~kg} \mathrm{ha}^{-1}$, resultando numa produção de $3274,5 \mathrm{~kg} \mathrm{ha}^{-1}$ durante o período de estudo. No plantio de E. urograndis a produção de serapilheira variou de 38,5 a $685,1 \mathrm{~kg}$ $\mathrm{ha}^{-1}$, registrando uma produção anual de $3523 \mathrm{~kg} \mathrm{ha}^{-1}$ durante o período avaliado.

Em um estudo da Embrapa Cerrados conduzido por (Melo e Resck, 2003) onde avaliaram o retorno de nutrientes no solo sob o plantio de $E$. camaudulensis no Cerrado do Distrito Federal, encontraram maior produção de serapilheira nos meses mais úmidos do ano, o mesmo foi encontrado por (Kolm e Poggiani, 2003) que avaliaram E. grandis, dados estes que corroboram com o presente estudo.

Fernandes, (2006) afirma que plantios realizados em ecossistemas tropicais demonstram uma produção continua de serapilheira durante todo ano, onde apresenta diferença na produção de acordo com as variações climáticas e do tipo de vegetação.

Quando analisado as frações separadas (folhas) e (material lenhoso) para cada mês, nos dois plantios de E. urocam e E. urograndis, a produção mensal de serapilheira total mostrou-se bastante variável. A menor deposição das folhas ocorreu entre os meses de menor precipitação de julho a outubro de 2015, ocorrendo também em dois meses no início do período chuvoso (novembro e dezembro de 2015), seguido de um aumento nos meses de maior precipitação junho de 2015 e janeiro a abril de 2016 e maior deposição no mês de maio de 2015 (339,3 Kg ha $\left.^{-1}\right)$ (Figura 4).

Já a fração material lenhoso obteve maior produção nos meses de junho de 2015 e fevereiro de 2016, os demais meses mostraram menor aporte de material lenhoso não diferindo estatisticamente entre si $(\mathrm{p}<0,05)$ (Figura 5). Portanto a fração lenhosa não demostrou ter correlação com a hidroperiodicidade, fato este que possivelmente o material lenhoso tem sua queda ligada ao desenvolvimento ou degradação natural da madeira do que pelo fator climático (Melo e Resck, 2003).

Figura 4. Produção de folha, registrada no período de maio de 2015 a abril de 2016, nos plantios de E. urocam e E. urograndis, Fazenda Nossa Senhora Aparecida, localizada no município de Aliança do Tocantins - TO. Letras iguais nas barras indicam igualdade significativa $(\mathrm{p}<0,05)$.

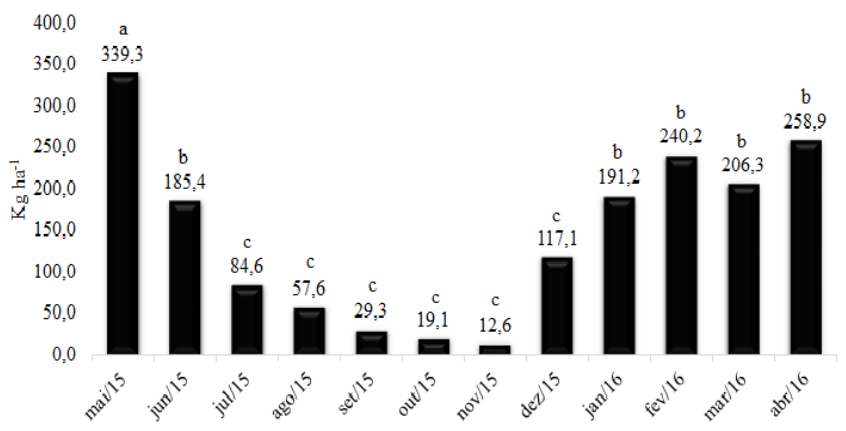

Figura 5. Produção de material lenhoso, registrada no período de maio de 2015 a abril de 2016, nos plantios de $E$. urocam e E. urograndis, Fazenda Nossa Senhora Aparecida, localizada no município de Aliança do Tocantins - TO. Letras iguais nas barras indicam igualdade significativa $(\mathrm{p}<0,05)$.

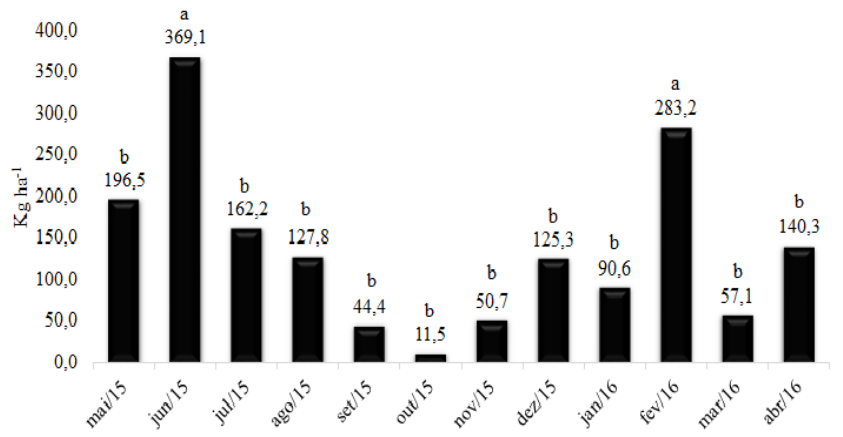

Por se tratar de uma monocultura, foi possível observar e inferir que a deposição de 
serapilheira nos plantios de E. urocam e E. urograndis apresentaram-se diferentes dos dados encontrados em floretas tropicas. Segundo (Barnes et al., (1998) as folhas representam o compartimento mais importante na maioria dos estudos de produção de serapilheira em florestas tropicais e essa fração depende principalmente das espécies, da estrutura do local e da idade das árvores. (Zimmermann et al., 2002) afirmam que as arvores das florestas tropicais estão em constante produtividade, por causa das trocas resultantes de altas taxas fotossintéticas, diferentes fenologias entre as espécies locais e pelas respostas mais rápidas às alterações ambientais (Barreto et al., 2007).

Ao analisar as frações separadas dentro de cada plantio E. urocam e E. urograndis pode observar que o plantio de E. urocam mostrou maior deposição de serapilheira da fração folha nos meses de janeiro e fevereiro de 2016, seguido pelos meses de maio e junho de 2015 e março e abril de 2016, já as menores deposições de folha ocorreram entre os meses de julho a dezembro de 2015 (Figura 6).

Figura 6. Produção mensal de folha, registrada no plantio de E. urocam, Fazenda Nossa Senhora Aparecida, localizada no município de Aliança do Tocantins - TO, no período de maio de 2015 a abril de 2016. Letras iguais nas barras indicam igualdade significativa $(\mathrm{p}<0,05)$.

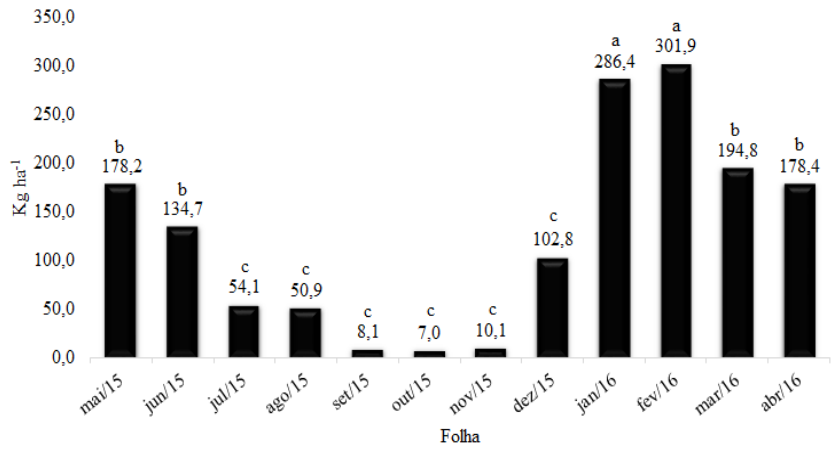

O plantio de E. urograndis apresentou maior deposição da fração folha no mês de maio de 2015, seguido do mês de abril de 2016. Os meses de junho de 2015, fevereiro e março de 2016 apresentaram-se iguais estatisticamente ao nível de $\mathrm{p}<0,05$ já as menores deposições da fração folha ocorreu entre os meses de julho de 2015 a janeiro de 2016 (Figura 7).

Segundo (Schumacher et al, 2004) a queda das folhas está ligada ao processo de senescência, que é o resultado de uma cadeia de processos metabólicos ligados à fisiologia de cada espécie, e também pelos estímulos vindos do ambiente, como fotoperíodo, temperatura e estresse hídrico. Em outro trabalho realizado pelo mesmo autor, onde avaliou os aspectos da ciclagem de nutrientes em talhões de três espécies de Eucalyptus localizados em Anhembi-SP, obteve resultados diferentes para as três espécies, no que se refere ao aporte da fração folha ao longo das diferentes estações do ano. Concluindo assim que a deposição de folhas não pode ser correlacionada apenas com as variáveis climáticas, edáficas e genéticas, sendo necessária uma análise no contexto geral tendo em vista as características de cada espécie.

Figura 7. Produção mensal de folha, registrada no plantio de E. urograndis, Fazenda Nossa Senhora Aparecida, localizada no município de Aliança do Tocantins - TO, no período de maio de 2015 a abril de 2016. Letras iguais nas barras indicam igualdade significativa $(\mathrm{p}<0,05)$.

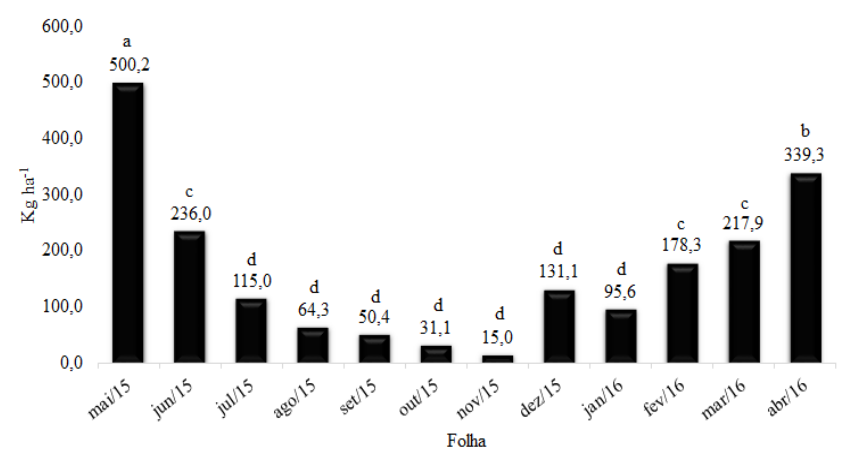

O plantio de E. urocam mostrou maior deposição na fração material lenhoso nos meses de maio, junho, julho e dezembro de 2015 e fevereiro de 2016, diferindo estatisticamente, ao nível de $\mathrm{p}<0,05$, dos meses de agosto a novembro de 2015, janeiro, março e abril de 2016 (Figura 8). 
Enquanto que o plantio de E. urograndis apresentou maior deposição de material lenhoso apenas no mês de junho de 2015, os demais meses mostraram-se significativamente iguais ao nível de $\mathrm{p}<0,05$ (Figura 9).

Analisando a deposição de serapilheira nos dois plantios de E. urocam e E. urograndis pode-se inferir que o maior aporte de material lenhoso ocorreu no plantio de E. urocam pois o mesmo tem sido influenciado pelas condições climáticas adversas como maior incidência de ventos, chuvas além do calor excessivo - efeito de borda.

Figura 8. Produção mensal de material lenhoso, registrada no plantio de E. urocam, Fazenda Nossa Senhora Aparecida, localizada no município de Aliança do Tocantins - TO, no período de maio de 2015 a abril de 2016. Letras iguais nas barras indicam igualdade significativa $(\mathrm{p}<0,05)$.

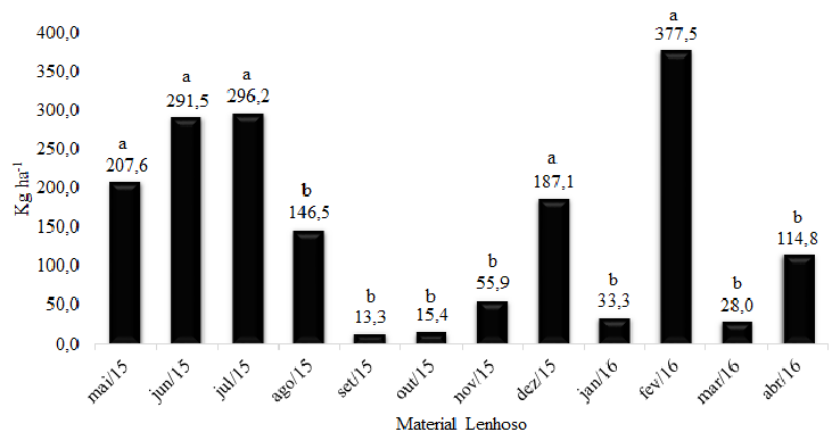

Figura 9. Produção mensal de material lenhoso, registrada no plantio de E. urograndis, Fazenda Nossa Senhora Aparecida, localizada no município de Aliança do Tocantins - TO, no período de maio de 2015 a abril de 2016. Letras iguais nas barras indicam igualdade significativa $(\mathrm{p}<0,05)$.

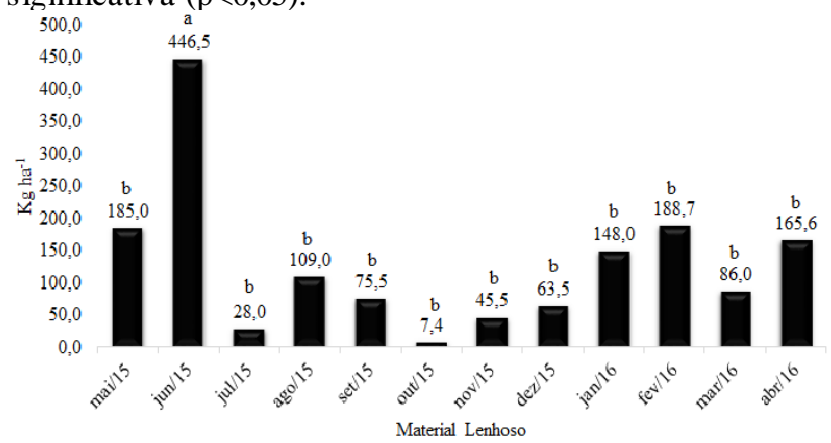

O plantio de E. urograndis contribuiu com

$56,7 \%\left(1974,1 \mathrm{Kg} \mathrm{ha}^{-1}\right)$ da deposição total de folhas e o plantio de E. urocam contribuiu com 53,3\% (1767 $\mathrm{Kg} \mathrm{ha}^{-1}$ ) do total de material lenhoso depositado.

O maior aporte de folhas no plantio de $E$. urograndis possivelmente explica-se por apresentar maior quantidade de folha em sua copa, em relação ao plantio de E. urocam, característica observada durante o estudo.

\section{CONCLUSÃO}

A maior deposição de serapilheira total foi encontrada no plantio de E.urograndis com $51,8 \%$ do total de serapilheira. Enquanto que o plantio de $E$. urocam contribuiu com $48,2 \%$.

A deposição mais representativa da serapilheira em ambos os plantios E. urocam e $E$. urograndis foi a fração folha, onde contribuiu com $51,2 \%$ do total de serapilheira depositada.

Já a fração material lenhoso representou $48,8 \%$ da serapilheira total depositada, onde demostrou ter mais relação com a incidência de ventos do que com as condições climáticas.

Todos os autores declararam não haver qualquer potencial conflito de interesses referente a este artigo.

\section{REFERÊNCIAS}

BARRETO, L.; ARZABE, C.; LIMA,Y.C.C. Herpeto fauna da região de Balsas. In Cerrado Norte do Brasil - North Cerrado of Brazil (L. Barreto, ed.). USEB, Pelotas, p. 221-229, 2007.

BARNES, B.V.; ZAK, D.R.; DENTON, S.R.; SPURR, S.H. Forest Ecology. Editora John Wiley, New York, 774p, 1998.

CALDEIRA, M. V. W.; VITORINO, M. D.; SCHAADT, S. S.; MORAES, E.; BALBINOT, R. Quantificação de serapilheira e de nutrientes em uma Floresta Ombrófila Densa Semina: Ciências Agrárias, Londrina, v. 29, n. 1, p. 53-68, 2008.

CARREIRA, R.C. Germinação em sementes de Miconia albicans (Sw.) Triana e Miconia rubiginosa (Bonpl.) DC., Melastomataceae, do Cerrado de Mogi 
Guaçu, SP. 2004. 143f. Dissertação de Mestrado, Instituto de Botânica, São Paulo, 2004.

CORREIA, M.E.F; ANDRADE, A.G. Formação de serapilheira e ciclagem de nutrientes. In: SANTOS, G.A.; SILVA, L.S.; CANELLAS, L.P.; CAMARGO, F.A.O. (Ed.) Fundamentos da matéria orgânica do solo: ecossistemas tropicais \& subtropicais. 2. ed. rev. e atual. - Porto Alegre: Metropole, 2008. cap. 10, p.137-158.

FERNANDES, M. M.; PEREIRA, M. G.; MAGALHÃES, L. M. S.; CRUZ, A. R.; GIÁCOMO, R. G. Aporte e decomposição de serapilheira em áreas de floresta secundária, plantio de sabiá (Mimosa caesalpiniaefolia Benth.) e Andiroba (Carapa guianensis Aubl.) na flona Mário Xavier, RJ. Ciência Florestal, Santa Maria, v. 16, n. 2, p. 163175. 2006.

FERREIRA, D.F. SISVAR: um programa para análises e ensino de estatística. Revista Symposium, Lavras, v. 6, n. 2, p. 36-41, 2008.

KOLM, L.; POGGIANI, F. Ciclagem de nutrientes em povoamentos de Eucalyptus grandis submetidos à pratica de desbastes progressivos. Scientia Forestalis, Piracicaba, v. 63, p. 79-93, 2003.

MELO, J. C. de. O fenômeno El Niño e as secas no Noerdeste do Brasil. Raízes, Campina Grande, v. 18, n. 20, p. 13-21, 1999

MELO, J. T. de; RESCK, D. V. S. Retorno ao solo de nutrientes de serapilheira de Eucalyptus camaldulensis no Cerrado do Distrito Federal. Embrapa Cerrados, Planaltina, p.17, 2003. (Boletim de Pesquisa e Desenvolvimento/Embrapa Cerrados, 109).

OLIVEIRA, A. D. de; SCOLFORO, J. R. S.; SILVEIRA, V. DE P. Análise econômica de um sistema agro-silvo-pastoril com eucalipto implantado em região de Cerrado. Ciência Florestal, Santa Maria, v.10, n.1, p.1-19, 2000.

REIS, M. G. F.; BARROS, N. F. Ciclagem de nutrientes em plantios de eucalipto. In BARROS, $\mathrm{N}$. F.; NOVAIS, R. F. (Ed.). Relação solo-eucalipto. Viçosa: Folha de Viçosa, 1990. p. 265-301.

RONDON, J.N. Autoecologia de Bauhinia holophylla Steud. (Leguminosae- Cesalpinoide) na Reserva
Biológica e Estação Experimental de Mogi Guaçu, SP. 2006. 76f. Tese de Doutorado. Universidade Estadual de Campinas, São Paulo, 2006.

SANTANA, J. A. S.; VILAR, F. C. R.; SOUTO, P. C.; ANDRADE L. A. de. Acumulo de serapilheira em plantios puros e em fragmento de mata atlântica na Floresta Nacional de Nisia Floresta-RN. Revista Caatinga, Mossoro, v. 22, n. 3 p. 59-66, 2009.

SAYER, E. J. Using experimental manipulation to assess the roles of leaf litter in the functioning of forest ecosystems. Biol. Rev., 80: 1-31, 2005.

SEAGRO, N 2016. Tocantins é o estado de maior cres cimento em silvicultura, diz Embrapa. Palmas: Secretaria de Agricultura e Pecuaria, 2012. Disponivel em: http $/ /$ seagro.to.gov.br/noticia/2012/5/10/tocantins-eo-estado-de-maior-crescimento-em-silvicultura-dizembrapa/. Acesso em: 07 de setembro de 2016.

SCHUMACHER, M. V; BRUN, E. J.; HERNANDES, J. I.; KÖNIG, F. G. Produção de serapilheira em uma floresta de Araucaria angustifolia (Bertol.) Kuntze no município de Pinhal Grande - RS. Revista Árvore, Viçosa, v.28, n.1, p.29-37, 2004.

ZIMMERMANN, S.; BRAUN, S.; CONEDERA, M.; BLASER, P. Macronutrient inputs by litterfall as opposed to atmospheric deposition into two contrasting chestnut forest stands in southern Switzerland. Forest Ecology and Management, v.161, p. 289-302, 2002.

WATZLAWICK, L.F.; KIRCHNER, F.F.; SANQUETTA, C.A.; SCHUMACHER, M.V. Fixação de carbono em floresta ombrófila mista em diferentes estágios de regeneração. In: SANQUETTA, C.R., WATZLAWICK, L.F. BALBINOT, R. ZILIOTTO, M.A., GOMES, F.S. (Org.) As florestas e o carbono. Curitiba: UFPR, 2002. p.153-173.

WERNECK, M.S.; PEDRALLI, G.; GIESEKE, L.F. Produção de serapilheira em três trechos de uma floresta semidecídua com diferentes graus de perturbação na Estação Ecológica do Tripuí, Ouro Preto. Revista Brasileira de Botânica, São Paulo, v. 24, n. 2, p.1, 2001. 